\title{
Germinação e crescimento inicial de híbridos de meloeiro em função da salinidade
}

\author{
Roberto Cleiton F de Queiroga²; Romeu de C Andrade Neto' ${ }^{1}$; Glauber Henrique de S Nunes ${ }^{1}$; José \\ Francismar de Medeiros ${ }^{1}$; Wildjaime de B M de Araújo ${ }^{1}$
}

${ }^{1}$ ESAM-Dep ${ }^{\text {to }}$ Fitotecnia, C. Postal 137, 59625-900 Mossoró-RN; ${ }^{2}$ UFV-Dep ${ }^{\text {to }}$ Fitotecnia, 36571-000 Viçosa-MG; robertocleiton@hotmail.com

\section{RESUMO}

As áreas de cultivo com intensa evaporação, deficiência em drenagem e uso inadequado de fertilizantes têm aumentado os problemas com a salinidade prejudicando o rendimento das culturas. No meloeiro as elevadas concentrações de sais no solo e na água ocasionam modificações morfológicas, estruturais e metabólicas, que inibem o seu crescimento e desenvolvimento. Portanto, o objetivo deste trabalho foi avaliar a germinação e o crescimento inicial de híbridos de meloeiro em diferentes níveis de salinidade da água de irrigação e submetidas a um estresse salino através da embebição. Os tratamentos foram instalados no delineamento inteiramente casualizado em esquema fatorial $2 \times 3 \times 5$ (sementes tratadas com e sem pré-embebição em solução salina de $\mathrm{NaCl}(6 \mathrm{~g} / \mathrm{L})$, três híbridos de meloeiro (Hy Mark, Honey Dew Red Flesh e Daimiel), e cinco níveis de condutividade elétrica da água de irrigação $(0,45 ; 1,30$; 2,15; 3,00 e 3,85 $\mathrm{dS} \mathrm{m}^{-1}$ ), com três repetições. Foram feitas avaliações da porcentagem de germinação, velocidade de emergência, área foliar, altura e massa seca da parte aérea. O tratamento prégerminativo de sementes de meloeiro com solução salina $(6 \mathrm{~g} / \mathrm{L})$ proporcionou maior massa seca da parte aérea das plântulas e um aumento significativo na porcentagem de germinação. Por outro lado, a salinidade da água de irrigação reduziu a área foliar, a massa seca da parte aérea da plântula e a altura da plântula. A cultivar Daimiel destacou-se como a mais tolerante a salinidade em razão das maiores estimativas da área foliar, massa seca da parte aérea e altura da plântula.

Palavras-chave: Cucumis melo L., plântulas, produção, osmocondicionamento.

\begin{abstract}
Germination and initial growth stage of melon plant hybrids due to salinity

Cultivation sites with intense evaporation rates, drainage deficit and inadequate use of fertilizers have increased the problems with salinity by impairing the good development of cultures. In melon plants, the high concentration of salts in both soil and water bring about morphological, structural and metabolic changes and inhibit their growth and development. Therefore, the aim of this work was to evaluate germination and initial growth stage of melon plants hybrids in different levels of salinity of irrigation water and submitted to a saline stress through imbibition. The treatments were organized in a completely randomized design in factorial scheme $2 \times 3 \times 5$ (seeds treated with and without preimbibition in saline solution of $\mathrm{NaCl}(6$ $\mathrm{g} / \mathrm{L})$, three hybrids of melon plant Hy Mark, Honey Dew Red Flesh and Daimiel, and five levels of electrical conductivity of irrigation water $\left(0.45 ; 1.30 ; 2.15 ; 3.00\right.$ and $\left.3.85 \mathrm{dS} \mathrm{m}^{-1}\right)$, with three replicates. Evaluation of germination rate, emergency speed, foliar area, height and dry mass of the aerial part were made. The pre-germinant treatment of melon plant seeds with saline solution $(6 \mathrm{~g} / \mathrm{L})$ provided larger dry mass of the aerial part of seedlings and a significant increase in the percentage of germination. On the other hand, the salinity of irrigation water reduced the foliar area, the dry mass of the aerial part and the height of the seedling. Compared to the other two cultivars, Daimiel proved to be the most tolerant to salinity due to higher estimates of the foliar area, dry mass of the aerial part and the height of the seedling.
\end{abstract}

Keywords: Cucumis melo L., seedlings, production, osmoconditioning.

(Recebido para publicação em 17 de maio de 2005; aceito em 21 de agosto de 2006)

$\mathrm{O}$ melão é a hortaliça de maior importância nos últimos anos no nordeste brasileiro devido ao aumento das exportações, ao maior consumo no mercado interno e a ocupação de grande quantidade de mão-de-obra (Medeiros, 2001). A região nordeste, representada pelos estados do Rio Grande do Norte, Ceará, Bahia e Pernambuco, respondeu por $93,4 \%$ da produção do país em 2001 (IBGE, 2003). O Rio Grande do Norte destaca-se como o principal produtor dessa olerícola, tanto em área cultivada como em produtividade (Medeiros, 2001). A produção de melão neste esta- do se concentra no pólo agrícola Mossoró-Açu e na Chapada do Apodi, englobando a região semi-árida, próxima à zona litorânea, na qual predominam altos níveis de sais no solo e na água de irrigação. Nessas áreas, a intensa evaporação, a deficiência em drenagem e o próprio uso de fertilizantes, têm aumentado os problemas com a salinidade, prejudicando o rendimento das culturas (Medeiros, 2001).

Espécies e cultivares apresentam tolerância variável à salinidade (Gohram, 1995), o que faz com que a necessidade e o manejo da lixiviação de sais no solo sejam específicos para cada cultura. Os efeitos dos sais sobre as plantas podem ser notados pelas dificuldades de absorção de água salina pela planta, pela interferência dos sais nos processos fisiológicos, ou mesmo por toxidez, similares àquelas de adubações excessivas (Lima, 1997).

O efeito geral da salinidade é a redução da taxa de crescimento, resultando em folhas menores e em menor número (Jacoby, 1994). As raízes também são reduzidas em seu comprimento e massa (Shannon \& Grieve, 1999). Chartozoulakis (1992), trabalhando com 
pepino, em condição salina acima de 5,0 $\mathrm{dSm}^{-1}$, verificou redução da germinação, no comprimento das radículas, nos pesos das massas fresca e seca das radículas, e para níveis entre 10,7 e 16,2 $\mathrm{dS} \mathrm{m} \mathrm{m}^{-1}$, redução da emergência de plântulas. Na cultura do meloeiro, as elevadas concentrações de sais no solo e na água ocasionam modificações morfológicas, estruturais e metabólicas e inibem o seu crescimento e desenvolvimento, reduzindo a porcentagem de massa seca nas plantas (Sivritepe et al., 2003), no tamanho dos frutos e rendimento (Mendlinger \& Fossen, 1993). A salinidade, também, afeta a porcentagem de germinação e o índice de velocidade de germinação das sementes (Oliveira et al., 1998; Sivritepe et al., 2003).

A necessidade de desenvolver cultivares com elevada tolerância a sais, têm aumentado fortemente, na última década, devido ao aumento da salinidade, pois, em geral, as plantas não desenvolvem tolerância a sais, a menos que elas as desenvolvam em condições salinas (Sivritepe et al., 2003; Passam \& Kakouriotis, 1994). Uma tecnologia que pode ser utilizada para se produzir, economicamente, em condições de salinidade é a preparação da semente através do osmocondicionamento e a avaliação de cultivares tolerantes a condições salinas (Sivritepe et al., 2003).

Considerando que há variabilidade genética suficiente no germoplasma de meloeiro, como tem sido demonstrado por Oliveira et al. (1998), é necessário avaliar a tolerância de híbridos de meloeiro para orientar os programas de melhoramento genético e a recomendação de materiais para essas regiões. $\mathrm{O}$ objetivo deste trabalho foi avaliar a germinação e o crescimento inicial de híbridos de melão quando submetidos a um estresse salino, através da embebição das sementes, e irrigação em diferentes níveis de salinidade.

\section{MATERIAL E MÉTODOS}

$\mathrm{O}$ experimento foi realizado em casa-de-vegetação da ESAM (MossoróRN), em setembro de 2003. O delineamento experimental utilizado foi o inteiramente casualizado, com três repetições. Os tratamentos foram instalados em esquema fatorial $2 \times 5 \times 3$ : sementes tratadas (com e sem pré-embebição em solução salina de $\mathrm{NaCl}$ a $6 \mathrm{~g} / \mathrm{L})$, três híbridos de meloeiro (Hy Mark, Honey Dew Red Flesh e Daimiel) e cinco níveis de salinidade da água $(0,45 ; 1,30$; 2,15; 3,00 e 3,85 dS m ${ }^{-1}$ ). O híbrido Hy Mark é do tipo Cantaloupe, o Honey Dew Red Flesh do tipo Orange Flesh, enquanto o Daimiel é do tipo Pele de Sapo.

Antes da condução definitiva do experimento, realizou-se um pré-ensaio com o objetivo de determinar o tempo ideal de embebição das sementes sem afetar o poder germinativo das mesmas. Este pré-ensaio foi realizado com duas soluções, com condutividade elétrica de 5,39 e $9,73 \mathrm{dS} \mathrm{m}^{-1}$, submetendo as sementes por 2, 4, 6, 8 e 10 horas nas soluções de $\mathrm{NaCl}$, nas concentrações citadas anteriormente, onde foram colocadas em placa de Petri contendo $50 \mathrm{~mL}$ das soluções, deixando-as embeber até o término do tempo estabelecido. Quando completado cada tempo, essas sementes foram retiradas da solução e imediatamente lavadas com água destilada, colocadas em papel germinativo e acondicionadas em câmara de germinação com temperatura regulada para $30^{\circ} \mathrm{C}$. Realizou-se a contagem das sementes germinadas, para determinar o melhor tempo de submersão e a melhor condutividade elétrica da água de embebição. A partir da porcentagem de germinação obtida, foi escolhida a solução com 9,73 dS m ${ }^{-1}(6 \mathrm{~g} / \mathrm{L}$ de $\mathrm{NaCl})$ e o tempo de 10 horas para embeber as sementes utilizadas no experimento.

No experimento foram usadas duas sementes de cada híbrido (tratadas ou não) em solução salina, em bandejas de 128 células contendo substrato comercial. Após quatro dias realizou-se o desbaste, deixando apenas uma planta para a contagem final. As bandejas foram colocadas em casa-de-vegetação e irrigadas durante 12 dias. A temperatura e umidade relativa do ambiente foram em média de $30^{\circ} \mathrm{C}$ e $70 \%$, respectivamente.

A solução usada para irrigação foi obtida misturando-se duas águas de diferentes poços com os níveis de salinidade de 0,45 e $3,85 \mathrm{dS} \mathrm{m}^{-1}$ em diferentes proporções, determinando a condutividade elétrica de cada mistura. A partir dos dados obtidos e suas respectivas proporções foi possível obter os níveis de condutividade elétrica da água de irrigação, espaçados em 0,85 dS $\mathrm{m}^{-1}$.

As características avaliadas foram porcentagem de germinação, obtida através da contagem do número de plantas germinadas por parcela e feita a transformação em porcentagem, velocidade de emergência (VE= $\mathrm{N}_{1} \mathrm{E}_{1}+\mathrm{N}_{2} \mathrm{E}_{2}+\ldots+\mathrm{N}_{\mathrm{n}} \mathrm{E}_{\mathrm{n}} / \mathrm{E}_{1}+\mathrm{E}_{2}+\ldots+\mathrm{En}$, onde $\mathrm{N}$ é o número de dias após o semeio e E é o número de plantas emergidas), altura da plântula, área foliar sendo determinada através de um integrador de área (marca LI-COR, modelo LI-3100) através da medida de todas as folhas de cada planta e pesada a massa seca da parte aérea após secagem em estufa com circulação forçada de ar a $70^{\circ} \mathrm{C}$.

Os dados foram submetidos à análise de variância ao nível de $1 \%$ de probabilidade. Os fatores qualitativos (híbrido e embebição), foram avaliados por meio de teste de comparação de médias, utilizando o critério de Scott-Knott com nível de significância de 5\%. O fator quantitativo (nível de salinidade) foi estudado através da análise de regressão. A análises foram realizadas pelo programa SAS (Statistical Analysis System), com os procedimentos GLM, REG e NLIN.

\section{RESULTADOS E DISCUSSÃO}

Quando as sementes foram embebidas em solução de cloreto de sódio, a porcentagem de germinação, bem como a massa seca da parte aérea foram significativamente maiores. Ao contrário, a velocidade de emergência das sementes embebidas com solução salina, foi significativamente menor (Tabela 1). Por outro lado, as cultivares diferiram para todas as características avaliadas, evidenciando variabilidade entre os híbridos de meloeiro. Considerando-se as interações entre os fatores avaliados, no presente estudo, não foi observada interação entre embebição e salinidade para quase todas as variáveis, exceto para velocidade de emergência. Constatou-se efeito significativo da interação 
Tabela 1. Velocidade de emergência, porcentagem de germinação, massa seca da parte aérea de plântulas com e sem embebição em solução de $\mathrm{NaCl}$ e de três híbridos de meloeiro, e desdobramento da interação para área foliar. Mossoró, ESAM, 2003.

\begin{tabular}{|c|c|c|c|c|c|c|}
\hline \multirow[t]{2}{*}{ Embebição (NaCl) } & \multirow{2}{*}{$\begin{array}{l}\text { Velocidade de } \\
\text { emergência } \\
\text { (dias) }\end{array}$} & \multirow{2}{*}{$\begin{array}{c}\text { Porcentagem } \\
\text { de germinação } \\
(\%)\end{array}$} & \multirow{2}{*}{$\begin{array}{c}\text { Massa seca } \\
\text { da parte } \\
\text { aérea (g) }\end{array}$} & \multicolumn{3}{|c|}{$\begin{array}{c}\text { Área foliar }\left(\mathrm{cm}^{2}\right) \\
\text { Desdobramento embebição } x \text { híbrido }(\mathrm{ExH})^{\star}\end{array}$} \\
\hline & & & & Hy Mark & H.D. Red Flesh & Daimiel \\
\hline Sem embebição com $\mathrm{NaCl}$ & $4,95 \mathrm{a}$ & $92,15 b$ & $1,36 \mathrm{~b}$ & 71,69 b A & 68,69 b A & 83,92 a $B$ \\
\hline Com embebição em $\mathrm{NaCl}$ & $4,78 \mathrm{~b}$ & 94,55 a & $1,49 \mathrm{a}$ & 72,06 b A & 65,91 b A & 98,64 a A \\
\hline \multicolumn{7}{|l|}{ Híbridos } \\
\hline Hy Mark & $4,70 \mathrm{~b}$ & $93,61 \mathrm{~b}$ & $1,32 \mathrm{~b}$ & - & - & - \\
\hline Honey Dew Red Flesh & $4,80 \mathrm{~b}$ & 95,55 a & $1,24 \mathrm{~b}$ & - & - & - \\
\hline Daimiel & $5,08 \mathrm{a}$ & $90,89 \mathrm{~b}$ & $1,76 \mathrm{a}$ & - & - & - \\
\hline
\end{tabular}

Médias seguidas pela mesma letra minúscula na coluna não diferem entre si pelo teste de Scott-Knott a 5\% de probabilidade.

* $(\mathrm{ExH})$ - Médias seguidas pela mesma letra minúscula na linha, e maiúscula na coluna, não diferem entre si pelo teste de Scott-Knott a 5\% de probabilidade.

entre embebição e híbridos apenas para a área foliar. Houve interação significativa entre híbridos e salinidade para a variável altura da plântula.

Observou-se um efeito quadrático para as sementes tratadas com solução de $\mathrm{NaCl}$, as quais apresentaram menor número de dias para a emergência das plântulas, em comparação com as não tratadas, a partir de $0,80 \mathrm{dS} \mathrm{m}^{-1}$ (Figura 1). O fato de ter havido interação embebição x salinidade para a velocidade de emergência deve está relacionado ao ajustamento osmótico, ou seja, a embebição das sementes fizeram com que elas se ajustassem à salinidade da água a qual foram submetidas, resultando numa maior velocidade de emergência. Talvez o ajustamento tenha apenas respondido na fase de emergência, ao contrário do que poderia ocorrer na fase final de crescimento culminando numa menor quantidade de massa seca. Dentre os híbridos, o Hy Mark e o Honey Dew Red Flesh apresentaram menor número de dias para a emergência das plântulas em relação ao Daimiel (Tabela 1).

Para a porcentagem de germinação, as sementes tratadas com $\mathrm{NaCl}$ apresentaram maior valor do que as não tratadas (Tabela 1). Esse resultado indica que o tratamento da semente do meloeiro com solução de $\mathrm{NaCl}$ aumentou significativamente a porcentagem de germinação, embora tenha ocorrido pequena diferença na germinação de sementes tratadas e não tratadas. O híbrido Honey Dew Red Flesh apresentou maior porcentagem de germinação que os demais (Tabela 1), o que não corrobora com

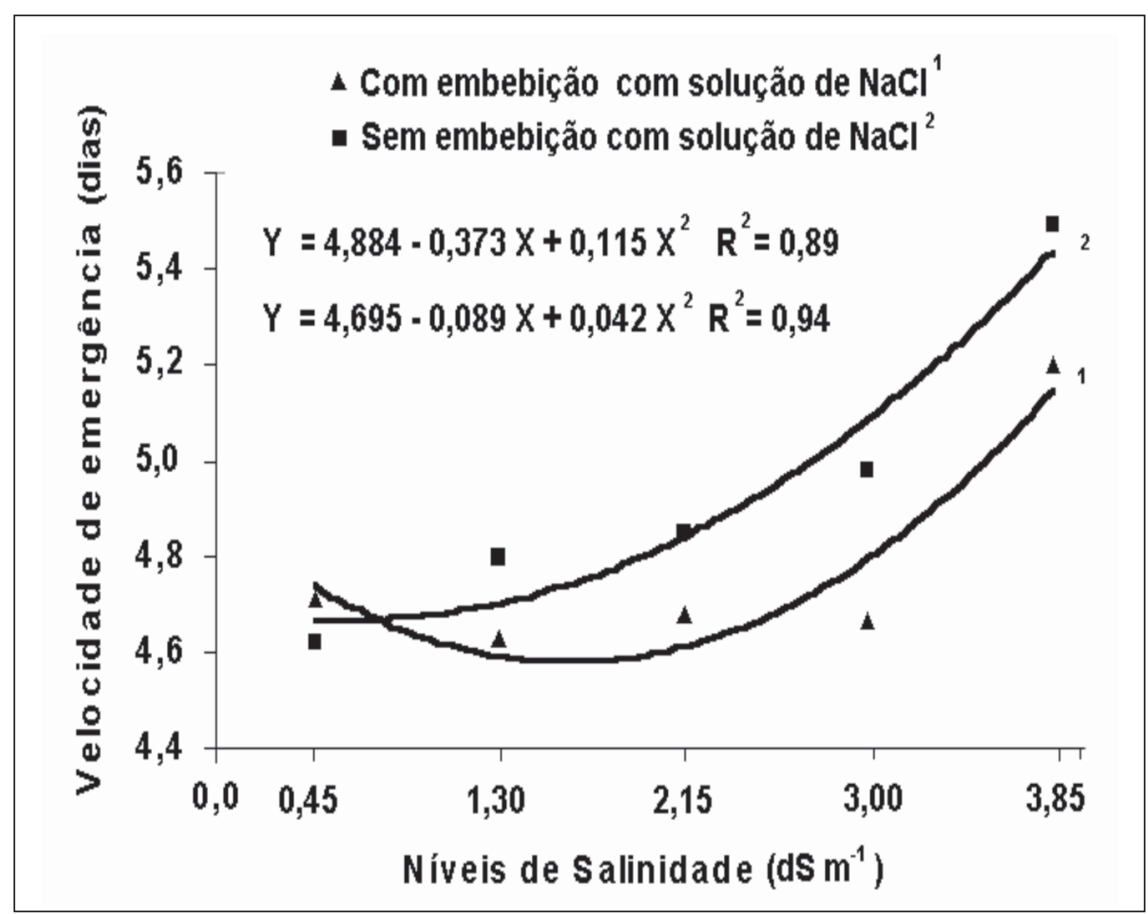

Figura 1. Velocidade de emergência de sementes de híbridos de meloeiro com (1) e sem (2) embebição com solução salina em função de níveis de salinidade da água de irrigação. ESAM, Mossoró, 2003.

resultados de área foliar, massa seca e altura da plântula para esse híbrido. A diferença entre os três híbridos não é elevada, no entanto, a porcentagem de germinação do híbrido Daimiel é alta, evidenciando que esse material é tolerante à salinidade da água de irrigação. Em estudo realizado para comparar o efeito da salinidade sobre a germinação de sementes de híbridos de meloeiro Botía et al. (1998) verificaram efeito negativo da salinidade sobre a germinação, diferente dos resultados obtidos. Sivritepe et al. (2003), trabalhando com sementes de meloeiro, observaram que as sementes que passaram por um tratamento pré-germinativo com $\mathrm{NaCl}$ apresentaram melhores resultados para a emergência total e tempo médio de emergência.

Para velocidade de emergência e porcentagem de germinação, os resultados sugerem que as sementes embebidas em solução de $\mathrm{NaCl}$ passaram por um processo de adaptação à salinidade, originado da osmorregulação, que pode ser induzida por solutos orgânicos (açúcares, ácidos orgânicos, aminoácidos livres e prolinas) e/ou íons específicos $(\mathrm{Na}, \mathrm{Ca}$ e $\mathrm{Cl})$, evitando também a desi- 


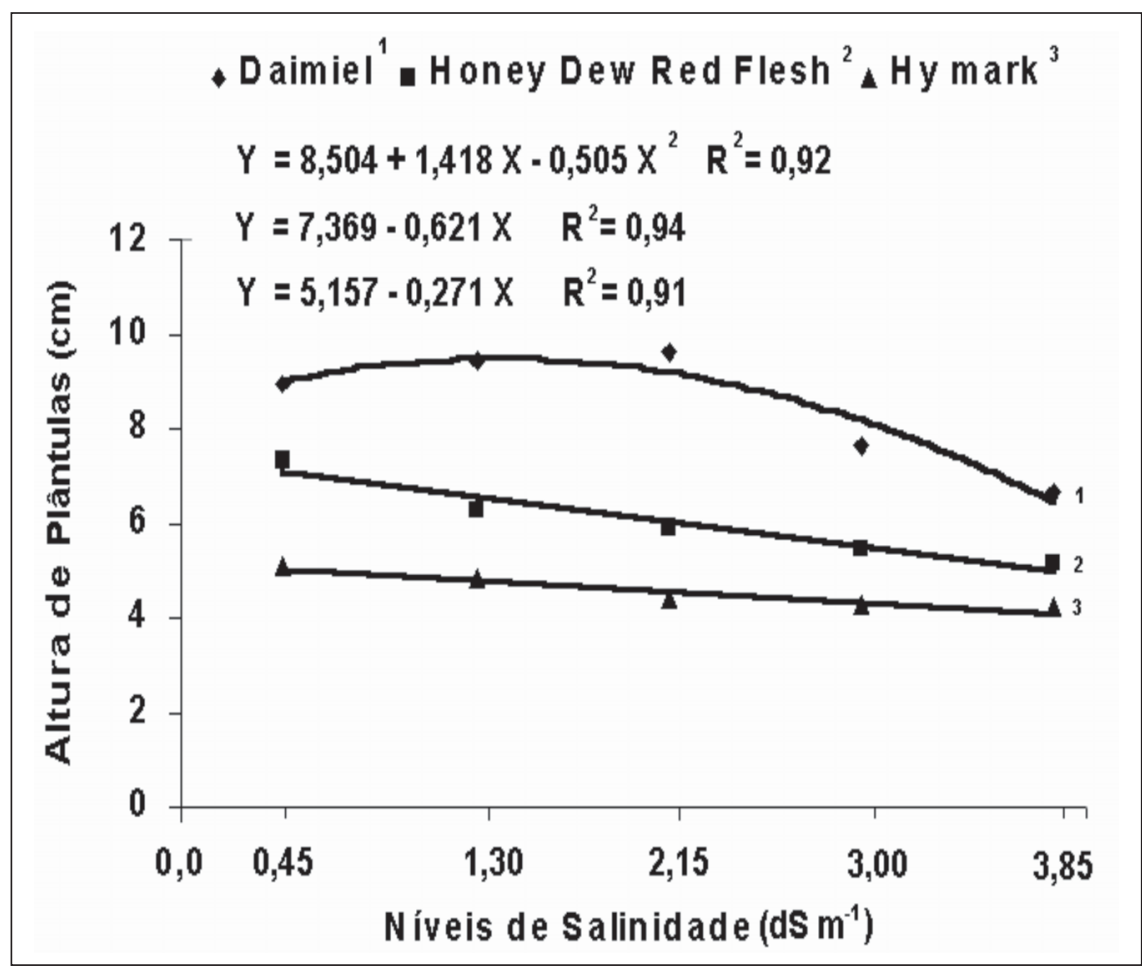

Figura 2. Altura das plântulas de meloeiro híbrido Daimiel (1), Honey Dew Red Flesh (2) e Hy Mark (3) em função de níveis de salinidade da água de irrigação. Mossoró, ESAM, 2003,

dratação, o qual é a base da sua tolerância a sais, induzida por estresse osmótico.

As plântulas provenientes de sementes embebidas apresentaram maior massa seca da parte aérea (Tabela 1). O híbrido Daimiel (grupo Inodorus) apresentou maior massa seca em relação aos demais. Mangal et al. (1988), trabalhando com melões dos grupos inodorus e cantaloupensis, também constataram diferenças entre cultivares para a massa seca.

Para a área foliar, constatou-se que o híbrido Daimiel apresentou maior área foliar nas condições de sementes embebidas em solução salina e que não se verificaram diferenças entre os híbridos Hy Mark e Honey Dew Red Flesh (Tabela 1).

A altura de plântulas não foi influenciada pela embebição da semente em solução de $\mathrm{NaCl}$.

No que se refere ao efeito dos níveis de salinidade da água de irrigação, observou-se que seu aumento reduziu a altura das plântulas nos três híbridos, apresentando efeito quadrático no híbrido Daimiel, que foi afetado negativamente a partir de $2,15 \mathrm{dS} \mathrm{m}^{-1}$ (Figura 2) em relação aos outros dois, que apre- sentaram uma resposta linear, inversamente proporcional ao aumento nos níveis de salinidade da água de irrigação. O híbrido Hy Mark, com a menor estimativa de altura de plântula, apresentou o menor declínio, seguido do híbrido Honey Dew Red Flesh. O comportamento do híbrido Daimiel foi distinto dos demais, demonstrando mais tolerância a maiores níveis de salinidade da água de irrigação. $\mathrm{O}$ resultado para altura de plântula para o híbrido Daimiel está coerente com aqueles observados nas variáveis área foliar e massa seca da plântula (Tabela 1). Nukaya et al. (1980), estudando o efeito da salinidade sobre genótipos de meloeiro, verificaram efeito negativo da salinidade sobre a altura de plantas, em dois estádios da colheita.

Houve uma resposta linear dos níveis de salinidade da água de irrigação, influenciando de forma negativa a área foliar, evidenciando que, o desenvolvimento das folhas é prejudicado pelo aumento da salinidade da água de irrigação (Figura 3A), concordando com os resultados de Franco et al. (1997). O índice de área foliar é uma característica que tem sido recomendada para avaliar a tolerância de genótipos ao estresse salino. Em outras culturas, seja perene ou anual, tem sido demonstrando que a salinidade reduz a área foliar, comprometendo o crescimento da plântula e, por conseqüência, a produtividade (Azevedo Neto \& Tabosa, 2000; Carneiro et al., 2002). Houve uma redução significativa de $17,61 \%$ na área foliar do nível de $0,45 \mathrm{dS} \mathrm{m}^{-1}$ para $3,85 \mathrm{dS} \mathrm{m}^{-1}$ de salinidade da água de irrigação, a qual é inferior àquelas observadas em trabalhos realizados na Espanha (Franco et al., 1993; Franco et al., 1997). Vale ressaltar que os níveis utilizados nesse estudo foram inferiores àqueles dos trabalhos acima citados, além das cultivares serem diferentes, visto que cada cultivar possuem suas características intrínsecas.

Franco et al. (1997) comentam que o índice de área foliar está estreitamente relacionado com a produção sob estresse salino, com correlações próximas de 1,0, entre área foliar e produção. As injúrias induzidas por sais podem ocorrer não somente devido a efeitos osmóticos e oxidativos, mas também por efeitos tóxicos e de deficiência de nutrientes (Sivritepe et al., 2003). O aumento nos níveis de salinidade pode causar o aumento na concentração de $\mathrm{Na}$ e levar a redução nos teores de $\mathrm{K}$ e $\mathrm{Ca}$ nas plântulas do meloeiro. O Ca altera a permeabilidade da membrana plasmática, e com a salinidade pode, afetar a entrada de outros nutrientes, o que é um dos principais fatores do estresse das plantas. Já o K, por meio da ativação enzimática, síntese de proteínas e fotossíntese, afeta a divisão e expansão celular, proporcionando plantas com menor área foliar.

Houve efeito linear da massa seca da parte aérea das plântulas (Figura 3B) que apresentou variação inversamente proporcional com o aumento dos níveis de salinidade da água de irrigação, conforme havia sido verificado para a área foliar. Houve uma redução de 23,57 \% da massa seca do nível de salinidade da água de irrigação de $0,45 \mathrm{dS} \mathrm{m}^{-1}$ para $3,85 \mathrm{dS} \mathrm{\textrm {m } ^ { - 1 }}$, sendo mais acentuada a partir de 2,15 $\mathrm{dS} \mathrm{m}^{-1}$. Isso concorda com a literatura, isto é, o meloeiro é uma cultura moderadamente tolerante à salinidade até condutividade elétrica de $2,2 \mathrm{dS} \mathrm{m}^{-1}$ no extrato de saturação do solo (Mangal et al., 1988; Mendlinger e Pasternak, 1992). Feigin (1990), estu- 
dando respostas de plantas de meloeiro Gália em condições salinas $\left(9,0 \mathrm{dS} \mathrm{m}{ }^{-1}\right)$ e não salinas, em solução nutritiva, obteve menor quantidade de massa seca. Desta forma, o aumento nos níveis de salinidade contribuiu para a redução da área foliar e, consequentemente, redução na capacidade fotossintética das plântulas, na massa seca e síntese de carboidratos, conforme verificado por Sivritepe et al. (2003).

Diante dos resultados obtidos, conclui-se que o tratamento de sementes de melão com solução salina de $\mathrm{NaCl}$ (6 g/ L) pode ser usado para aumentar a tolerância de sais pelas plântulas, proporcionando maior massa seca da plântula e aumento na porcentagem de germinação. O híbrido Daimiel destacou-se como o mais tolerante à salinidade, em razão dos maiores valores de área foliar e massa seca da parte aérea, quando as sementes foram embebidas em solução salina.

\section{REFERÊNCIAS}

AZEVEDO NETO AD; TABOSA JN. 200. Estresse salino em plântulas de milho: parte I análise do crescimento. Revista Brasileira de Engenharia Agrícola e Ambiental 4: 159-164.

BOTÍA P; CARVAJAL M; CERDÁ A; MARTÍNEZ V. 1998. Response of eight Cucumis melo cultivars to salinity during germination and early vegetative growth Agronomie 18: 503-513.

CARNEIRO PT; FERNANDES PD; GHEYI HR SOARES FAL. 2002. Germinação e crescimento inicial de genótipos de cajueiro anão precoce em condicões de salinidade. Revista Brasileira de Engenharia Agrícola e Ambiental 6: 199-206.

CHARTOZOULAKIS KS. 1992. Effects of $\mathrm{NaCl}$ salinity germination, growth and yield of greenhouse cucumber. The Journal of Horticultural Science 67: 115-119.

FEIGIN A. 1990. Interactive effects of salinity and ammonium/nitrate ratio on growth and chemical composition of melon plants. Journal of Plant Nutrition 13: 1257-1269.

FRANCO JA; FERNÁNDEZAJ; BANÓN S. 1997. Relationship between the effects of salinity on seedling leaf area and fruit yield of six muskmelon cultivars. HortScience 32: 642-644.

FRANCO JA; ESTEBAN C; RODRIGUEZ C. 1993. Effects of salinity on various growth stages of muskmelon cv. Revigal. The Journal Horticultural Science 68: 899-904.

GORHAM J. 1995. Sodium content of agricultural crops. In : PHILLIPS CJC; CHIV PC (eds). Sodium in Agriculture. Canterbury. Chalcombe Publications. p. 17-32.

IBGE. 2003, 13 fevereiro. Indicadores conjunturais - produção agrícola/agricultura. Disponível em http://www.ibge.gov.br/

JACOBY B. 1994. Mechanisms involved in salt tolerance by plants. In: Pessarakli M (Eds) Handbook of Plant and Crop Stress. New York: Marcel Dekker. p. 97-123.

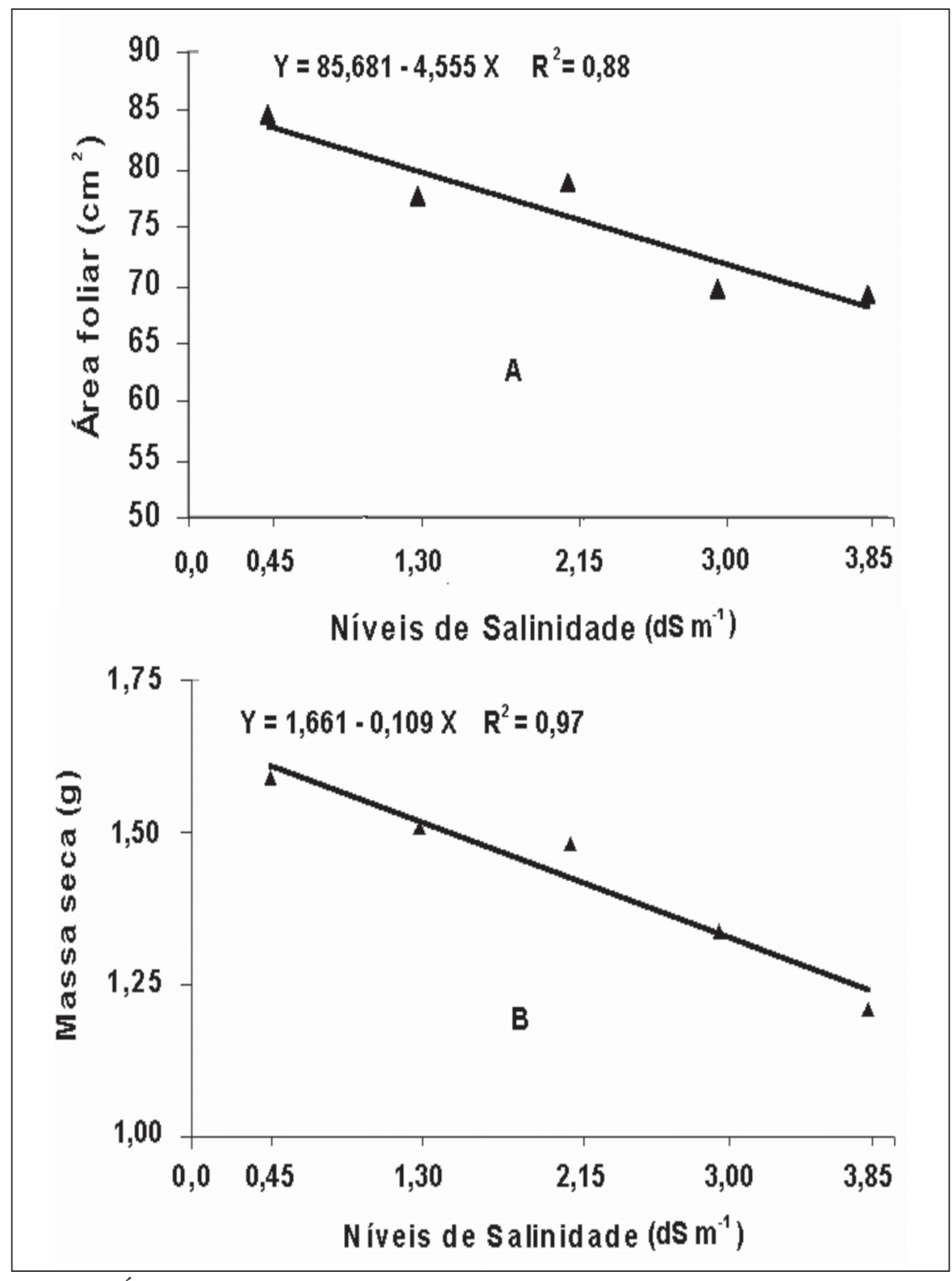

Figura 3. Área foliar (A) e massa seca da parte aérea (B) de plântulas de híbridos de meloeiro em função dos níveis de salinidade da água de irrigação. Mossoró, ESAM, 2003.

LIMA LA. 1997. Efeitos dos sais no solo e na planta. In: GHIYI HR; QUEROZ JE; MEDEIROS $\mathrm{JF}$ (eds): Manejo e controle da salinidade na agricultura irrigada. Campina Grande-PB: UFPB. p. 113-136.

MANGAL JL; HOODA PS; LAL S. 1988. Salt tolerance of five muskmelon cultivars. The Journal Agricultural Science 110: 641-663.

MEDEIROS PH. 2001. Pontos Críticos no Manuseio de Frutos Exportados Via Porto de Natal. Mossoró: ESAM. 42p (Monografia).

MENDLINGER S; FOSSEN M. 1993. Flowering, vegetative growth, yield, and fruit quality in muskmelons under saline conditions. The Journal of American Society for Horticultural Science 118: 868-872.

MENDLINGER S; PASTERNAK D. 1992. Effect of time of salinization on flowering, yield and fruit quality factors in melon, Cucumis melo L. The Journal of Horticultural Science 67: 529-534.
NUKAYA A; MASUI M; ISHIDA A. 1980. Salt tolerance of muskmelon grown in different salinity soils. Journal Japanese Society Horticultural Science 28: 468-474.

OLIVEIRA PM; BLANBK AF; PEREIRA AJ; LIMA LA. 1998. Efeito da salinidade da água sobre a germinação de cultivares de melão. Revista Brasileira de Engenharia Agrícola e Ambiental 2: 235-238.

PASSAM HC; KAKOURIOTIS D. 1994. The effects of osmoconditioning on the germination, emergence and early plant growth of cucumber under saline conditions. Scientae Horticulturae 57: 233-240.

SHANNON MC; GRIEVE CM. 1999. Tolerance of vegetable crops to salinity. Scientia Horticulturae 78: 5-38.

SIVRITEPE N; SIVRITEPE HO; ERIS A. 2003. The effect of $\mathrm{NaCl}$ priming on salt tolerance in melon seedling grown under saline conditions. Scientae Horticulturae 97: 229-237. 